\title{
Air Pollution Characteristics and Meteorological Correlates in Lin'an, Hangzhou, China
}

\author{
Xintao Lin, Jian Chen*, Ting Lu, Dongming Huang, Jing Zhang \\ The State Key Laboratory of Subtropical Silviculture, Zhejiang A \& F University, Lin'an, Hangzhou 311300, China
}

\begin{abstract}
The concentration and distribution of atmospheric particulate matter depend primarily on the meteorological conditions associated with a fixed pollution source. The effects of meteorological factors on particulate matter have been analyzed on the meteorological seasonal scale, but few researchers have considered the climatic season, which is divided based on the distribution feature of climatic factors. In addition, the hysteresis effect of meteorological factors is easily neglected. Here, we reviewed the characteristics and influential factors of particle pollution based on particle concentration and meteorological data from January 2013 through December 2013. Results from nonparametric tests and Spearman's nonparametric correlation coefficient showed that particle pollution exhibited a statistically significant seasonal trend. The pollution on workdays was slightly less than that on holidays, but no significant difference was found. The air pressure 1-2 days earlier showed a higher positive correlation with the current particle concentrations (except in winter), and the temperature 2-3 days earlier in summer and fall showed a stronger negative correlation with the particle concentration. Lower moisture and frequent precipitation would significantly reduce the pollution on the current day and the next day (except in summer). The variation of particulate matter concentration in summer exhibited a high-low-high variation, caused mainly by temperature and precipitation; the air quality during the plum rain period was significantly better than that in the period before the plum rain. The fine particle pollution level during the high-temperature and heat wave days was the lowest, after which the concentration increased.
\end{abstract}

Keywords: Particulate matter; Meteorological factors; Climatic season; Hysteresis effect; Temporal variation.

\section{INTRODUCTION}

In 2013, hazy weather widely appeared across a large area in central and eastern China. The visibility was excessively low for a long time, and the economic loss was huge. According to the bulletin on the state of the environment in China for 2014 (http://www.cnemc.cn/jcbg/zghjzkgb/20170 6/W020181008686126902641.pdf), among 74 cities in China, only three meet the air quality standard. From the perspective of various indexes, the compliance rate of $\mathrm{PM}_{2.5}$ is the lowest and accounts for only $4.1 \%$ of the monitored cities, followed by $\mathrm{PM}_{10}$. Therefore, $\mathrm{PM}_{2.5}$ and $\mathrm{PM}_{10}$ continue to be the primary air pollutants in cities.

There are various sources of atmospheric particulate matter, including natural sources, e.g., crust, dust, and sea salt, and anthropogenic sources, e.g., coal combustion, the smelting industry, and motor vehicle exhaust (Sun et al., 2004; Yang et al., 2006; Huang et al., 2012). The chemical composition

\footnotetext{
${ }^{*}$ Corresponding author.

Tel.: +86-571-61105258

E-mail address: chenjian@126.com
}

of atmospheric particulate matter is complex; coarse particulate matter is usually dominated by primary particles, and fine particulate matter is dominated by secondary ions (e.g., $\mathrm{SO}_{4}{ }^{2-}$ and $\mathrm{NO}_{3}{ }^{-}$) formed by $\mathrm{SO}_{2}$ and $\mathrm{NO}_{\mathrm{x}}$ through homogeneous and inhomogeneous reactions (Finlayson-Pitts, 2009; Hassan et al., 2013; Liang et al., 2018). Previous studies indicate that atmospheric particulate matter is subject to direct and indirect effects of multiple meteorological factors (e.g., temperature, relative humidity, wind speed, and atmospheric pressure) on emission, transfer, formation, and deposition processes (Hien et al., 2002; Xu et al., 2015; Zhang et al., 2015; Li et al., 2019). However, there is no consensus among scholars on the influence of various meteorological factors on particulate matter, and contrasting conclusions on the effect of the same meteorological factor on the particulate matter have been drawn. For example, a recent study reported that when $\mathrm{PM}_{2.5}$ pollution in Beijing city was serious, the relative humidity was relatively high, while the opposite occured in Guangzhou city (Zhang et al., 2015).

Most meteorological factors have obvious seasonal characteristics, it is the same with the particulate matter pollution. Previous research has shown that the dominant meteorological factors that influence atmospheric pollution are different in the four seasons (Tian et al., 2014). Therefore, 
the effects of meteorological factors on particulate matter are always analyzed on the seasonal scale. The meteorological season, that is, the seasons divided by month, is mostly used (Ito et al., 2007; Li et al., 2019). Several results have been concluded when analyzing the meteorological effects in different meteorological seasons. However, this method of seasonal division does not take geographical and climatic factors into account. A climatic season can be defined as an independent stage in the annual cycle of the climatic component of the natural environment, and closely related to phenological development in nature (Jaagus and Ahas, 2000). The emission of biogenic volatile organic compounds (BVOCs) varies from phenology to phenology (Bai et al., 2017), while BVOCs may be closely related to particulate matter pollution (Heal et al., 2011). Therefore, the climatic seasonal division based on the distribution features of climatic factors is utilized to analyze the seasonal variation of particulate matter and meteorological factors, improving the understanding of the mechanisms driving the response of particles to meteorological conditions. Additionally, the effect of meteorological factors on current pollution has been the focus of most researchers. However, their neglect of the hysteresis effect of meteorological factors on the concentration of particulate matter needs further exploration (Huang et al., 2015).

Numerous studies in China are mostly concentrated in the urban regions of Beijing, Shanghai, and the Pearl River Delta region (Li et al., 2009; Zhang et al., 2015; Guo et al., 2017; Li et al., 2019), while relevant studies in the Yangtze Delta region are limited. As a representative area of the Yangtze River Delta region, Lin'an is a typical subtropical climate region; however, an understanding of the characteristics and influential factors of particulate matter pollution is lacking. This study was based on atmospheric particulate matter data $\left(\mathrm{PM}_{10}\right.$ and $\left.\mathrm{PM}_{2.5}\right)$ collected over 12 consecutive months (January 2013-December 2013) in Lin'an District in Hangzhou. These data were combined with conventional meteorological factors (the pressure, the temperature, the relative humidity, the amount of precipitation, the wind speed, and the wind direction) to analyze and investigate the current state and influential factors of particulate matter pollution in Lin'an and to determine whether there were vital relationships between meteorological factors and particulate matter, thus deepening the basic understanding of the influence of meteorological factors on particulate matter and establishing a foundation for optimizing a prediction model of particulate matter pollution in the Yangtze River Delta region.

\section{METHODS}

\section{Research Site}

Lin'an, a representative region of the Yangtze River Delta area, is in the jurisdiction of Hangzhou city, located in the Tianmu Mountain area in northwestern Zhejiang Province. The geographic ranges are $29^{\circ} 56^{\prime} \mathrm{N}-30^{\circ} 23^{\prime} \mathrm{N}$ and $118^{\circ} 51^{\prime} \mathrm{E}-$ $119^{\circ} 52^{\prime} \mathrm{E}$, and the total area is $3118.77 \mathrm{~km}^{2}$. Lin'an has a typical subtropical marine monsoon climate, including high temperatures and frequent rain in summer, with mild temperatures and less rain in winter. In 2013, the residential population of Lin'an exceeded 0.527 million (Lin'an Yearbook for 2014). The terrain in the territory of Lin'an tilts from the northwest to the southeast, and it is surrounded by mountains on three sides, i.e., north, west, and south, forming a horseshoeshaped barrier in the southeast (Fig. S1). The populations in the western and southwestern regions are relatively small, and the population is dense in the northeastern and northern regions. This population distribution is connected to the Yangtze River Delta urban agglomeration. A previous study indicated that the characteristic of aerosol in Lin'an is similar to that of other big cities (Chen et al., 2012). In recent years, with the acceleration of industrialization and urbanization, the economy of Lin'an has rapidly developed, and the age and number of motor vehicles are rapidly increasing; further, the occurrence of hazy weather is becoming more frequent.

\section{Data Acquisition}

The data used in this study were obtained from the stereoscopic detection network of atmospheric compound pollution in Zhejiang Province, which were freely available online (http://aqi.zjemc.org.cn/aqi/flex/index.html). The daily average data of mass concentration (hereafter referred to as concentration $/ \mu \mathrm{g} \mathrm{m}^{-3}$ ) for $\mathrm{PM}_{10}$ and $\mathrm{PM}_{2.5}$ at two monitoring stations in Lin'an, i.e., the Fourth Middle School (119 $41^{\prime}$ 'E, $\left.30^{\circ} 14^{\prime} \mathrm{N}\right)$ and the Municipal Government Building $\left(119^{\circ} 42^{\prime} \mathrm{E}, 30^{\circ} 14^{\prime} \mathrm{N}\right.$ ) (the distance between the two stations is approximately $2.4 \mathrm{~km}$, Fig. S1), from January 2013 to December 2013 were downloaded. Then, the daily, monthly, and seasonally mean particle concentrations in Lin'an were calculated based on these two stations' data. In particular, the technique of particulate matter monitoring employed at the stations follows the Technical Specifications for Installation and Acceptance of Ambient Air Quality Continuous Automated Monitoring System for PM 10 and PM 2.5 (HJ655-2013).

The ground surface meteorological data for Lin'an include the atmospheric pressure ( $\mathrm{AP} ; \mathrm{hPa})$, the temperature $\left(\mathrm{T} ;{ }^{\circ} \mathrm{C}\right)$, the relative humidity $(\mathrm{RH} ; \%)$, the amount of precipitation (the amount of precipitation at $20 \mathrm{BJT}$ on the current day to $20 \mathrm{BJT}$ on the next day; hereafter referred to as precipitation, $\mathrm{P} ; \mathrm{mm}$ ), the wind speed (WS; $\mathrm{m} \mathrm{s}^{-1}$ ), and the wind direction corresponding to the highest wind velocity (hereafter referred to as the wind direction, WD, which is expressed by adopting 16 bearings). The distance between the Lin'an automatic meteorological observation station (station number: 58448, $119^{\circ} 41^{\prime} \mathrm{E}, 30^{\circ} 14^{\prime} \mathrm{N}$ ) and the two atmospheric quality monitoring stations is approximately $2.0 \mathrm{~km}-2.5 \mathrm{~km}$. And the daily data could be downloaded from the National Meteorological Information Center Science data-sharing service platform (http://data.cma.cn/site/index.html). These meteorological data were directly used to analyzed the relationship with particle concentration.

The meteorological seasons were divided as follows: meteorological spring (March, April and May), meteorological summer (June, July and August), meteorological fall (September, October and November), and meteorological winter (December, January and February).

The influence of weather conditions on the seasonal development of nature is the leading criterion for dividing a 
year into climatic seasons, and constant temperature thresholds are the most frequently used possibility for determining climatic seasons (Jaagus and Ahas, 2000). Refering to the climatic seasonal division issued by the China Meteorological Administration (QX/T 152-2012), and using the daily average temperature, the climatic seasons were divided as follows: climatic spring (March 4-May 18), climatic summer (May 19September 24), climatic fall (September 25-November 24), and climatic winter (November 25-December 31 and January 1-March 3).

Unless otherwise stated, the seasons appearing in this paper refer to the climatic season.

\section{Statistical Analysis}

The Kruskal-Wallis $\mathrm{H}$ test was used to analyze the differences in the distribution of particulate matter levels associated with the climatic season, the wind direction, and the period in summer. The data of particulate matter concentration and meteorological factors did not conform to a normal distribution (Shapiro-Wilk normality test, $p<0.05$ ) or homogeneity of variance (Levene's test, $p<0.05$ ). A DunnBonferroni test was chosen for post hoc comparisons. The Mann-Whitney U test was used to analyze the differences in particulate matter levels on workdays and public holidays. Spearman's nonparametric correlation analysis was used to analyze the relationships between particle levels and meteorological factors to better understand their relationships (Yadav et al., 2015). Statistical analysis of the data were performed in SPSS 25.0 (SPSS, IBM, USA), and the plots were plotted in Origin 2018 (Origin, Origin Lab, USA). The statistical results in this paper were expressed as the "mean \pm standard deviation". The significance level was set to 0.05 .

\section{RESULTS AND DISCUSSION}

Overview of Particulate Matter Pollution in Lin'an District In 2013, the annual average $\mathrm{PM}_{10}$ and $\mathrm{PM}_{2.5}$ concentrations in Lin'an were $105.88 \pm 59.46 \mu \mathrm{g} \mathrm{m}^{-3}$ and $59.54 \pm 44.34$ $\mu \mathrm{g} \mathrm{m}^{-3}$, respectively, greatly exceeding the yearly CAAQS (Chinese ambient air quality standards, GB 3095-2012) Grade II standards $\left(\mathrm{PM}_{2.5}=35 \mu \mathrm{g} \mathrm{m}^{-3}, \mathrm{PM}_{10}=70 \mu \mathrm{g} \mathrm{m}^{-3}\right)$. Compared with the provincial average in $2013, \mathrm{PM}_{2.5}$ was slightly lower, while $\mathrm{PM}_{10}$ was slightly higher $\left(\mathrm{PM}_{2.5}=\right.$ $61 \mu \mathrm{g} \mathrm{m}^{-3}, \mathrm{PM}_{10}=91 \mu \mathrm{g} \mathrm{m}^{-3}$; data obtained from the Bulletin for the Environment State of Zhejiang Province in 2013, http://www.zjepb.gov.cn). The $\mathrm{PM}_{2.5}$ pollution was likely related to the accelerated development of industrialization and an increase in motor vehicle ownership in Lin'an during. The burning of coal and fuel wood might be an important cause of $\mathrm{PM}_{10}$ pollution. (Liang et al., 2018).

The number of days that $\mathrm{PM}_{10}$ and $\mathrm{PM}_{2.5}$ met the daily CAAQS Grade II standards $\left(\mathrm{PM}_{2.5}=75 \mu \mathrm{g} \mathrm{m}^{-3}, \mathrm{PM}_{10}=150\right.$ $\mu \mathrm{g} \mathrm{m}^{-3}$ ) in 2013 was 305 and 287 days, respectively. When the $\mathrm{PM}_{2.5}\left(\mathrm{PM}_{10}\right)$ concentration exceeds the daily CAAQS Grade II standards, it is called a $\mathrm{PM}_{2.5}\left(\mathrm{PM}_{10}\right)$ pollution day. There were 8 days when the $\mathrm{PM}_{10}$ did not meet the standard, but the $\mathrm{PM}_{2.5}$ did meet the standard (Fig. 1); five of these days were in spring, two were in summer, and one day was in the fall, implying that the coarse particulate matter pollution was higher in spring. The occurrence of $\mathrm{PM}_{10}$ pollution was mostly accompanied by $\mathrm{PM}_{2.5}$ pollution (independence test, $\chi^{2}=179.09, \mathrm{~d} f=1, p \ll 0.001$ ). The compliance rate of $\mathrm{PM}_{10}$ reaching the daily CAAQS Grade II standards in July and August was 100\% (hereafter referred to as the compliance rate), and it was the lowest (35.5\%) in December. The compliance rate of $\mathrm{PM}_{2.5}$ in July, August, and September was $100 \%$, and it was the lowest $(22.6 \%)$ in January. The primary pollutant calculation results, with reference to the Chinese Technical Regulations on Ambient Air Quality Index (AQI) (on trial) (HJ633-2012) implemented in 2016, showed that $\mathrm{PM}_{2.5}$ was the primary pollutant for 129 days, whereas $\mathrm{PM}_{10}$ was the primary pollutant for 157 days in 2013. The data showed that atmospheric particulate matter was the primary pollutant causing air pollution in Lin'an. In particular, $\mathrm{PM}_{10}$ pollution was slightly more serious than $\mathrm{PM}_{2.5}$ pollution.

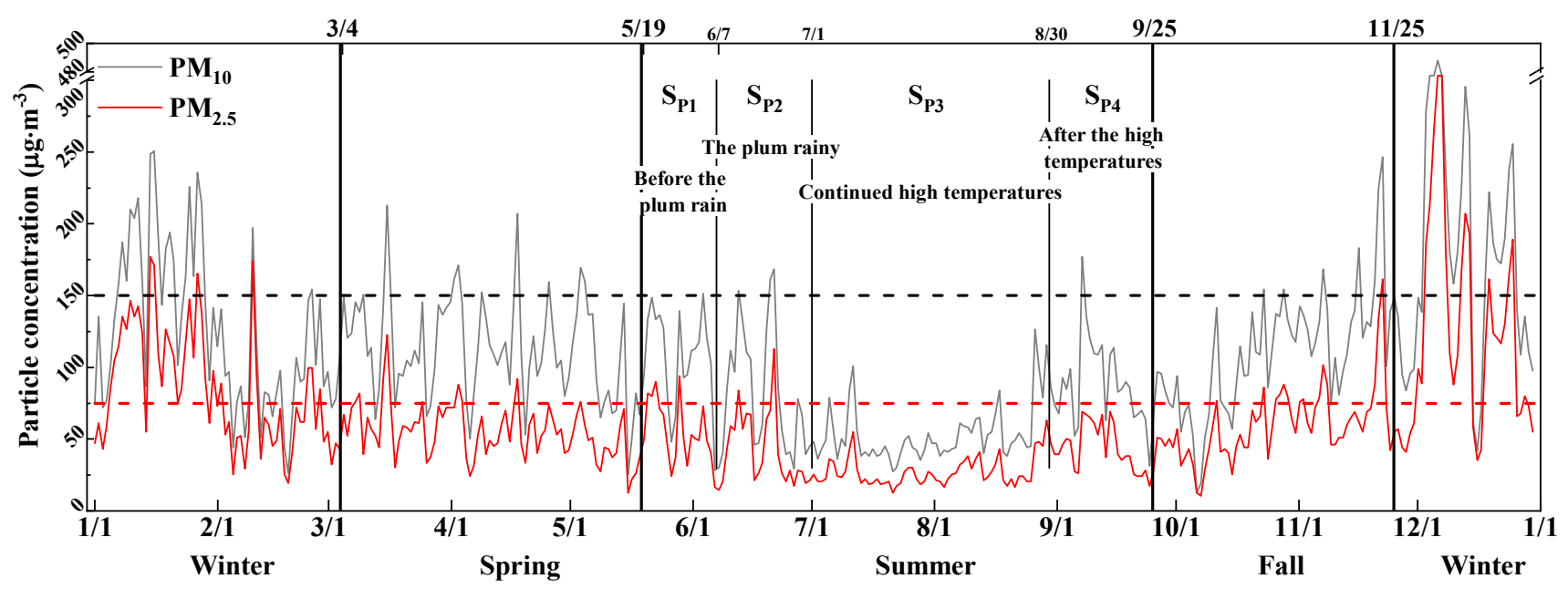

Fig. 1. Time series of particulate matter concentration. The red dotted line represents daily CAAQS Grade II standards of $\mathrm{PM}_{2.5}\left(75 \mu \mathrm{g} \mathrm{m}^{-3}\right)$, and the black dotted line represents daily CAAQS Grade II standards of PM $10\left(150 \mu \mathrm{g} \mathrm{m}{ }^{-3}\right)$. "S $\mathrm{S}_{\mathrm{P}}, \mathrm{S}_{\mathrm{P} 2}$, $\mathrm{S}_{\mathrm{P} 3}, \mathrm{~S}_{\mathrm{P} 4}$ " represent the four periods in summer. 
The concentration ratio of $\mathrm{PM}_{2.5}$ to $\mathrm{PM}_{10}\left(\mathrm{PM}_{2.5} / \mathrm{PM}_{10}\right)$, could reveal characteristics of particulate pollution ( $\mathrm{Li}$ et al., 2019). The annual $\mathrm{PM}_{2.5} / \mathrm{PM}_{10}$ in Lin'an was $0.54 \pm 0.11$. When $\mathrm{PM}_{2.5}$ pollution occured, $\mathrm{PM}_{2.5} / \mathrm{PM}_{10}$ was 0.65 , an increase of approximately 0.14 in comparison to the case when there was no $\mathrm{PM}_{2.5}$ pollution, similar to the results for the Yangtze River Delta region (Hu et al., 2014a). An increase in $\mathrm{PM}_{2.5} / \mathrm{PM}_{10}$ indicated that more secondary fine particulate matter may be generated, which therefore increased the proportion of fine particles when $\mathrm{PM}_{2.5}$ pollution occursed.

\section{Comparison of Particle Concentration Using Two Seasonal Division Methods}

The variation of particle in climatic seasons or in meteorological seasons were both analyzed (Table 1). There were several differences of results using these two seasonal division methods. The average concentrations of $\mathrm{PM}_{10}$ and $\mathrm{PM}_{2.5}$ in climatic summer were slightly higher than that in meteorological summer, while it was opposite in three other seasons (except for the $\mathrm{PM}_{2.5}$ of spring). However, significant differences were only found in summer (Mann-Whitney $U$ test). Coefficients of variation showed that the climatic seasonal division could lower the variation of particle in spring and summer, but increased it in fall and winter. This result may indicate the possibility of improving the accuracy of the particle prediction models in spring or summer when using climatic seasonal division.

In general, there were little particularly novel discoveries of particle concentration variation using climatic seasonal division compared to that using meteorological seasonal division, but it was still a good attempt. We still believe that the division of the climatic season would be more realistic than the meteorological season in a long-term sequence research of particulate matter pollution.

\section{Characteristics of the Temporal Variation of the \\ Particulate Matter}

Fig. 2 indicates that both $\mathrm{PM}_{10}$ and $\mathrm{PM}_{2.5}$ exhibited a seasonal trend, and both reached the 5\% significance level (Table 2). The Dunn-Bonferroni test indicated that the particulate matter concentration in winter was significantly higher than that in summer $\left(\mathrm{PM}_{10}\right.$ was approximately 2.04 times higher than that in summer, and $\mathrm{PM}_{2.5}$ was approximately 2.74 times higher than that in summer), while no statistically significant difference was found in the distribution of particulate matter concentration in the spring and fall (the average concentration of $\mathrm{PM}_{10}$ was approximately $108 \mu \mathrm{g} \mathrm{m}^{-3}$, and the average concentration of $\mathrm{PM}_{2.5}$ was approximately $55 \mu \mathrm{g} \mathrm{m}^{-3}$ ), which was consistent with the research on the seasonal evolution of particulate matter in the Lin'an area in recent years (Yue et al., 2017). In winter, particle concentration in December was higher than that in January and higher than that in February (Fig. 1), which may be related to the frequent use of wood and coal for heat by local residents in Lin'an. The atmospheric turbulence was relatively weak, and the thickness of the mixing layer was always small, so an

Table 1. Statistical summary of particulate matter concentration in two seasonal divisions.

\begin{tabular}{|c|c|c|c|c|c|c|c|}
\hline \multirow{2}{*}{ Variation } & & & \multirow{2}{*}{ Mean $\left(\mu \mathrm{g} \mathrm{m}^{-3}\right)$} & \multirow{2}{*}{$\begin{array}{l}\text { Standard } \\
\text { deviation }\end{array}$} & \multirow{2}{*}{$\begin{array}{l}\text { Coefficient of } \\
\text { variation }\end{array}$} & \multicolumn{2}{|c|}{ Mann-Whitney U test } \\
\hline & & & & & & $\bar{Z}$ & $p$ \\
\hline \multirow[t]{8}{*}{$\mathrm{PM}_{10}$} & Spring & Cli_S ${ }^{\#}$ & 111.470 & 35.708 & 0.320 & -0.459 & 0.646 \\
\hline & & Met_ $\mathrm{S}^{\#}$ & 109.240 & 35.253 & 0.323 & & \\
\hline & Summer & Cli_ $\overline{\mathrm{S}}$ & $71.790^{*}$ & 35.909 & 0.500 & -2.117 & 0.034 \\
\hline & & Met_S & $62.800^{*}$ & 33.881 & 0.540 & & \\
\hline & Fall & Cli_ $\bar{S}$ & 105.460 & 43.510 & 0.413 & -0.626 & 0.531 \\
\hline & & Met_S & 101.840 & 39.786 & 0.391 & & \\
\hline & Winter & Cli_s & 146.270 & 78.183 & 0.535 & -0.411 & 0.681 \\
\hline & & Met_S & 150.580 & 80.312 & 0.533 & & \\
\hline \multirow[t]{8}{*}{$\mathrm{PM}_{2.5}$} & Spring & Cli_ $\bar{S}$ & 53.330 & 18.807 & 0.353 & -0.048 & 0.962 \\
\hline & & Met_S & 53.380 & 19.324 & 0.362 & & \\
\hline & Summer & Cli_s & $35.560^{*}$ & 19.867 & 0.559 & -1.985 & 0.047 \\
\hline & & Met_S & $30.740^{*}$ & 17.867 & 0.581 & & \\
\hline & Fall & Cli_s & 56.670 & 25.914 & 0.457 & -1.205 & 0.228 \\
\hline & & Met_S & 52.380 & 23.530 & 0.449 & & \\
\hline & Winter & Cli_s & 97.330 & 62.203 & 0.639 & -0.796 & 0.426 \\
\hline & & Met_S & 102.520 & 62.885 & 0.613 & & \\
\hline \multirow[t]{8}{*}{$\mathrm{PM}_{2.5} / \mathrm{PM}_{10}$} & Spring & Cli_ $\bar{S}$ & 0.481 & 0.088 & 0.182 & -0.805 & 0.421 \\
\hline & & Met_S & 0.490 & 0.089 & 0.182 & & \\
\hline & Summer & Cli_ $\bar{S}$ & 0.491 & 0.079 & 0.161 & -0.357 & 0.721 \\
\hline & & Met_S & 0.489 & 0.076 & 0.155 & & \\
\hline & Fall & Cli_s & 0.542 & 0.092 & 0.170 & -1.605 & 0.108 \\
\hline & & Met_S & 0.517 & 0.097 & 0.187 & & \\
\hline & Winter & Cli_ $\bar{S}$ & 0.649 & 0.107 & 0.165 & -0.985 & 0.325 \\
\hline & & Met_S & 0.668 & 0.087 & 0.131 & & \\
\hline
\end{tabular}

\#"Cli S" represents "Climatic season"; "Met S" represents "meteorological season".

* represents the significant difference of particle between these two seasonal divisions at the 0.05 level (2-tailed). 

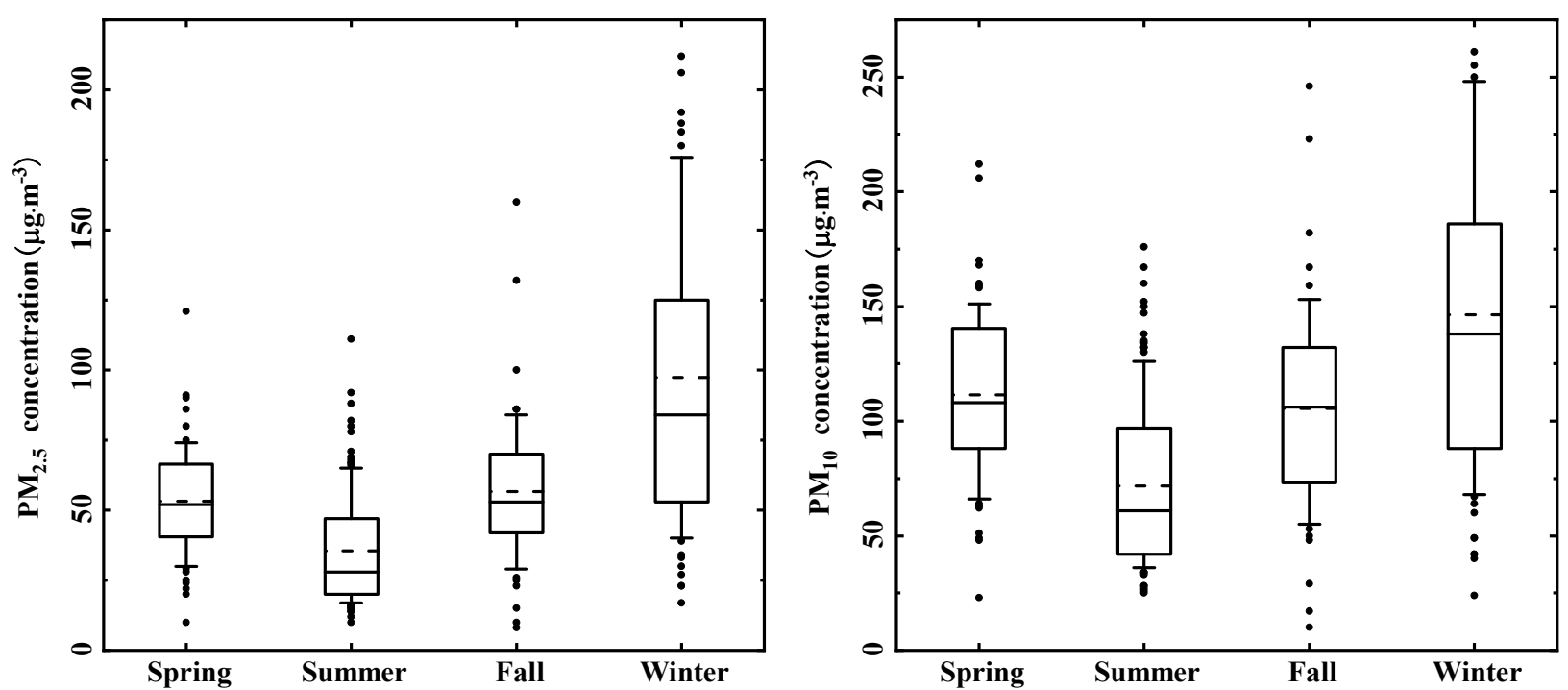

Fig. 2. Climatic seasonal variations of $\mathrm{PM}_{10}$ and $\mathrm{PM}_{2.5}$. The central box represents the values from the lower to upper quartile $\left(25^{\text {th }}-75^{\text {th }}\right.$ percentile). The vertical line extends from the $10^{\text {th }}$ percentile to the $90^{\text {th }}$ percentile. The middle solid line represents the median. The dash lines represent the arithmetic average. Outliers are plotted as dots.

Table 2. Significance tests of particulate matter levels for different climate season, wind direction, period in summer, workdays and holidays.

\begin{tabular}{|c|c|c|c|c|c|c|c|c|c|}
\hline \multirow{3}{*}{ Variable } & & \multicolumn{4}{|c|}{ Kruskal-Wallis H test } & \multicolumn{4}{|c|}{ Dunn-Bonferroni test } \\
\hline & & \multicolumn{2}{|c|}{$\mathrm{PM}_{2.5}$} & \multicolumn{2}{|c|}{$\mathrm{PM}_{10}$} & \multicolumn{2}{|c|}{$\mathrm{PM}_{2.5}$} & \multicolumn{2}{|c|}{$\mathrm{PM}_{10}$} \\
\hline & & $\mathrm{H}$ & $p$ & $\mathrm{H}$ & $p$ & $\mathrm{MD}$ & $p$ & $\mathrm{MD}$ & $p$ \\
\hline \multirow[t]{6}{*}{ Climate season } & Spr. vs. Sum. & 122.948 & 0.000 & 93.973 & 0.000 & 81.936 & 0.000 & 97.580 & 0.000 \\
\hline & Spr. vs. Fall. & & & & & -6.168 & 1.000 & 17.757 & 1.000 \\
\hline & Spr. vs. Win. & & & & & -72.791 & 0.000 & -31.948 & 0.283 \\
\hline & Sum. vs. Fall. & & & & & -88.104 & 0.000 & -79.823 & 0.000 \\
\hline & Sum. vs. Win. & & & & & -154.727 & 0.000 & -129.528 & 0.000 \\
\hline & Fall. vs. Win. & & & & & -66.622 & 0.001 & -49.705 & 0.023 \\
\hline \multirow{6}{*}{$\begin{array}{l}\text { Period in } \\
\text { summer* }\end{array}$} & $\mathrm{S}_{\mathrm{P} 1}$ vS. $\mathrm{S}_{\mathrm{P} 2}$ & 35.813 & 0.000 & 47.423 & 0.000 & 30.863 & 0.043 & 34.004 & 0.018 \\
\hline & $\mathrm{S}_{\mathrm{P} 1}$ vs. $\mathrm{S}_{\mathrm{P} 3}$ & & & & & 58.863 & 0.000 & 62.972 & 0.000 \\
\hline & $\mathrm{S}_{\mathrm{P} 1}$ vs. $\mathrm{S}_{\mathrm{P} 4}$ & & & & & 26.153 & 0.079 & 23.272 & 0.164 \\
\hline & $\mathrm{S}_{\mathrm{P} 2}$ vs. $\mathrm{S}_{\mathrm{P} 3}$ & & & & & 26.000 & 0.031 & 28.968 & 0.011 \\
\hline & $\mathrm{S}_{\mathrm{P} 2}$ vs. $\mathrm{S}_{\mathrm{P} 4}$ & & & & & -4.710 & 1.000 & -10.732 & 1.000 \\
\hline & $\mathrm{S}_{\mathrm{P} 3}$ Vs. $\mathrm{S}_{\mathrm{P} 4}$ & & & & & -30.710 & 0.001 & -39.700 & 0.000 \\
\hline \multirow{2}{*}{\multicolumn{2}{|c|}{ Wind direction }} & 52.616 & 0.000 & 48.093 & 0.000 & & & & \\
\hline & & Mann-W & nitney L & & & & & & \\
\hline \multirow{2}{*}{\multicolumn{2}{|c|}{ Workdays vs. Holidays }} & $\mathrm{Z}$ & $p$ & $\mathrm{Z}$ & $p$ & & & & \\
\hline & & -0.498 & 0.618 & -0.124 & 0.901 & & & & \\
\hline
\end{tabular}

*For the division of the four periods in summer, refer to section of "Characteristics of the particulate matter pollution in summer"

inversion layer easily appeared (Li et al., 2012), which was not favorable for the diffusion and dilution of pollutants. Therefore, the particulate matter pollution in winter far exceeded that in the three other seasons, and the compliance rate of particulate matter $(46.5 \%)$ was much lower than that in summer $(95.3 \%)$, and hazy weather likely occurred. Variation in particulate matter concentration in winter was likely driven by precipitation and windy weather (Fig. S2), and the fluctuation of particles was more obvious than that in the three other seasons. In summer, the air masses mostly originated from the eastern marine and coastal areas, and the air was relatively clean (Yue et al., 2017). Meanwhile, the unstable atmospheric stratification could accelerate the diffusion and dilution of particulate matter. Frequent precipitation, high temperature, and strong turbulent eddies could mitigate the pollution in summer, and caused a pretty air quality (Fig. S3).

Some studies indicated that the difference in human production and social activities on workdays and legal holidays caused a difference in the particulate matter concentration (Chen et al., 2016a; Yue et al., 2017), i.e., the "holiday effect", and there were regional differences in the strength and 
direction of this effect (Hu et al., 2014b; Huang et al., 2015). According to the circular of the General Office of the State Council regarding the schedule for the holidays in 2013 (http://www.gov.cn/zwgk/2012-12/10/content 2286598.htm), we divided 2013 into 250 workdays and 115 legal holidays. The average concentrations of $\mathrm{PM}_{10}$ and $\mathrm{PM}_{2.5}$ on the workdays were $104.35 \pm 55.46 \mu \mathrm{g} \mathrm{m}^{-3}$ and $57.71 \pm 39.24 \mu \mathrm{g} \mathrm{m}^{-3}$, respectively, which were lower than those on the legal holidays, by $4.86 \mu \mathrm{g} \mathrm{m}^{-3}$ and $5.82 \mu \mathrm{g} \mathrm{m}^{-3}$, respectively (Fig. 3). In addition, the $\mathrm{PM}_{2.5} / \mathrm{PM}_{10}$ ratio on workdays was lower by approximately 0.02 . In the seasonal scale, particle pollution on workdays was lower than that on legal holidays except for fall. The difference was lowest in spring and highest in winter, which was likely related to the relatively active atmosphere and the relatively frequent production and living activities of humans in spring. In fall, the precipitation frequency, the amount of precipitation, and the wind velocity on legal holidays were higher than those on workdays, which was conducive to removing particulate matter in the atmosphere. Therefore, there was less pollution on legal holidays. The Mann-Whitney $U$ test indicated that the differences in annual and seasonal particulate matter between workdays and legal holidays were not significant (Table 2), which was similar to the research results obtained for Nanjing (Chen et al., 2016a). Another phenomenon of particulate matter pollution on weekend was that it was lighter than in the middle of the week in Beijing from 2013-2014 (Huang et al., 2015), although it was insignificant.

\section{Influence of Meteorological Factors on the Particle Concentration}

The atmospheric particle concentration was primarily affected by meteorological conditions when the pollution source is relatively stable. There is a hysteresis effect of meteorological factors on particulate matter (Ito et al., 2007; Huang et al., 2015); therefore, the correlation between current various meteorological factors and the particulate matter concentration based on a delay by $0-3$ days was analyzed
(Table 3, Table S1). The results indicated that the pressure (986.6-1003.8 $\mathrm{hPa}$ ) was the lowest and the variation amplitude was narrow in summer but highest in winter (Fig. S4). The $\mathrm{PM}_{10}$ concentration in spring, summer, and fall was significantly positively correlated with the pressure 1-2 days earlier. The correlation coefficient in summer decreased with the number of lag days, but the opposite occurred in fall, i.e., atmospheric pressure 3 days earlier was highly correlated with the current $\mathrm{PM}_{10}$ concentrations. It is likely that the unstable atmospheric environment in summer accelerated the change in particulate matter concentration. A previous study found that horizontal dilution and vertical aggregation play a major role in $\mathrm{PM}_{2.5}$ pollution (Meng et al., 2019). In fall, the average surface wind speed decreased with increasing ground pressure (Fig. S5), which was not favorable for the diffusion of pollutants. In addition, the high ground pressure may cause a weakening of the vertical diffusion of particulate matter, resulting in increased pollution. Previous research found that the pressure gradient under high-pressure control in winter was large in the Yangtze River Delta, and low-level atmospheric airflow was obvious, which is conducive to the diffusion of pollutants (Wang et al., 2015), but a relatively weak diffusion effect was observed $(\mathrm{r}<-0.1$, insignificant difference). The correlation between $\mathrm{PM}_{2.5}$ and atmospheric pressure was essentially consistent with that observed for $\mathrm{PM}_{10}$.

The annual average temperature in Lin'an was approximately $16.89^{\circ} \mathrm{C}$ (Fig. S4). The seasonal average temperature in summer was higher than that in winter, by $24^{\circ} \mathrm{C}$, and the maximum difference in daily average temperature for the entire year was approximately $9.98^{\circ} \mathrm{C}$. The particle concentration and the air temperature exhibited a significant negative correlation in most seasons $\left(\mathrm{PM}_{10}\right.$ in spring and winter was insignificant). The correlation with the air temperature 2-3 days earlier was the strongest (Table 3), and the correlations in fall and summer were stronger than those in spring and winter, which was likely related to the constituent composition of the particulate matter in Lin'an.
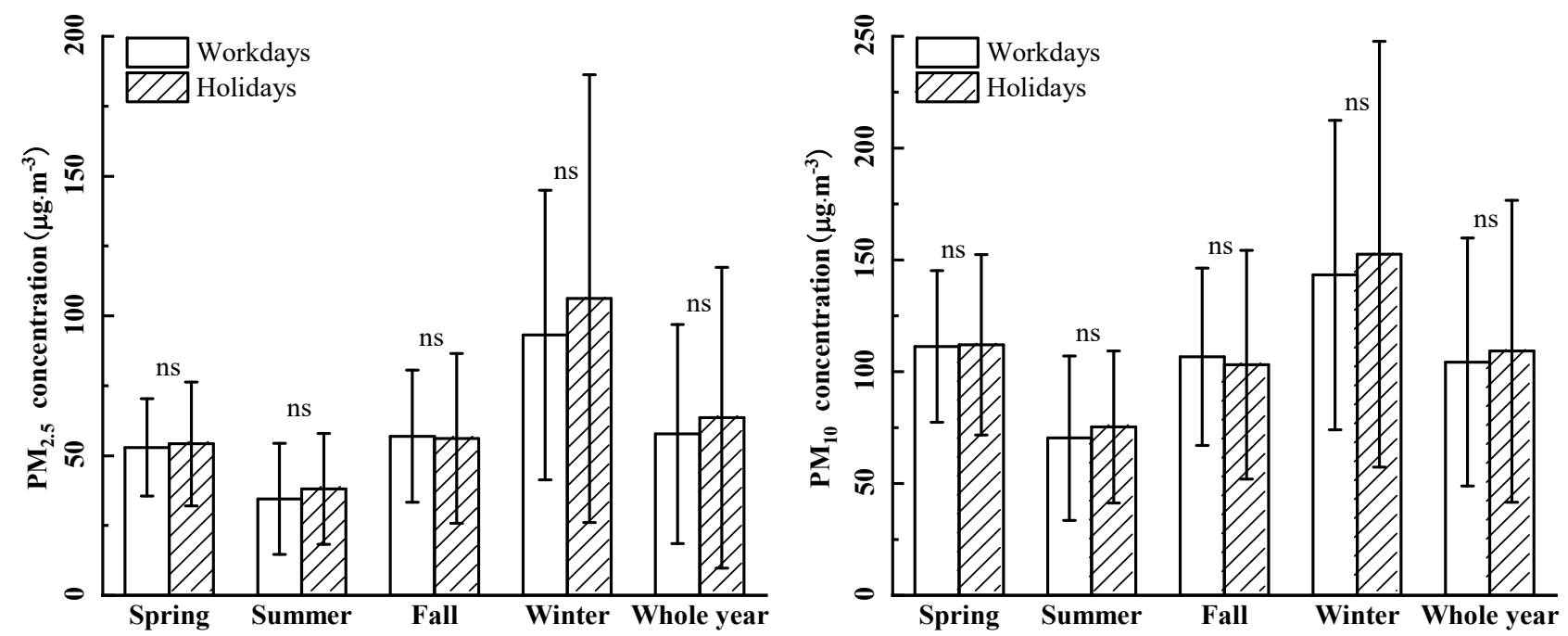

Fig. 3. Particulate matter concentrations on workdays and legal holidays. "ns" represents "no statistically significant difference is found at the level of 0.05 ". 
Table 3. Spearman correlation coefficient of current meteorology factors and particulate matter delayed by $0-3$ days.

\begin{tabular}{lllllll}
\hline & Climate seasons & AP & T & RH & P & WS \\
\hline $\mathrm{PM}_{10}$ & Spring & $0.363^{* *}(1)$ & $-0.222(2)$ & $-0.417^{* *}(1)$ & $-0.485^{* *}(1)$ & $-0.194(1)$ \\
& Summer & $0.529^{* *}(0)$ & $-0.514^{* *}(2)$ & $0.354^{* *}(0)$ & $-0.051(0)$ & $-0.315^{* *}(0)$ \\
& Fall & $0.569^{* *}(3)$ & $-0.661^{* *}(3)$ & $-0.355^{* *}(0)$ & $-0.322^{*}(0)$ & $-0.203(0)$ \\
& Winter & $-0.087(0)$ & $-0.146(3)$ & $-0.263^{* *}(1)$ & $-0.570^{* *}(1)$ & $-0.172(2)$ \\
& Whole & $0.558^{* *}(1)$ & $-0.600^{* *}(3)$ & $0.091(3)$ & $-0.325^{* *}(0)$ & $-0.327^{* *}(1)$ \\
$\mathrm{PM}_{2.5}$ & Spring & $0.314^{* *}(2)$ & $-0.284^{*}(2)$ & $-0.368^{* *}(1)$ & $-0.410^{* *}(1)$ & $-0.107(1)$ \\
& Summer & $0.493^{* *}(0)$ & $-0.429^{* *}(2)$ & $0.254^{* *}(3)$ & $-0.122(0)$ & $-0.341^{* *}(0)$ \\
& Fall & $0.573^{* *}(2)$ & $-0.589^{* *}(2)$ & $-0.337^{* *}(1)$ & $-0.371^{* *}(1)$ & $-0.354^{* *}(1)$ \\
& Winter & $-0.016(0)$ & $-0.238^{*}(3)$ & $-0.140(1)$ & $-0.453^{* *}(1)$ & $-0.226^{*}(2)$ \\
& Whole & $0.633^{* *}(2)$ & $-0.671^{* *}(2)$ & $0.116^{*}(3)$ & $-0.317^{* *}(1)$ & $-0.381^{* *}(1)$ \\
\hline
\end{tabular}

Note: Numbers highlighted in yellow indicate negative correlation, while numbers highlighted in red indicate positive correlation. The darker the color, the stronger the correlation. "**" represents the correlation is highly significant at the 0.01 level (2-tailed), while " " represents the correlation is significant at the 0.05 level (2-tailed). The numbers in parentheses represents the lag days with the strongest correlation.

In particular, the contribution rate of inorganic ions to the fine particulate matter has been reported to be approximately 40\%-60\% (Shi et al., 2017; Liang et al., 2018), and $\mathrm{SO}_{4}{ }^{2-}$, $\mathrm{NO}_{3}{ }^{-}$, and $\mathrm{NH}_{4}{ }^{+}$constitute approximately $90 \%$ of the inorganic ions. These ions are primarily formed by the transformation of $\mathrm{SO}_{2}$ and $\mathrm{NO}_{x}$. In recent years, due to the increase in the number of motor vehicles and the large amount of nitrogenous fertilizer applied to Phyllostachys praecox and Carya cathayensis, the proportions of nitrates and ammonium in the atmosphere have been increasing. Under high temperature conditions, some of the nitrates and the ammonium salts are unstable and easily decompose into gaseous pollutants ( $\mathrm{Li}$ et al., 2014), so the concentration of particulate matter decreased in summer and fall (the average temperature was $23.65^{\circ} \mathrm{C}$ ). In spring and winter, however, the low temperature (the average temperature was $9.56^{\circ} \mathrm{C}$ ) weakened the degradation of the above salt particles, and thus reducing its correlation with the concentration of particulate matter.

The quantity and frequency of precipitation in Lin'an were both high in summer and low in winter (Fig. 4). The total precipitation in summer accounted for $46.7 \%$ of the total annual precipitation. The precipitation occured every 2.3 days in spring and summer and every 3-4 days in fall and winter. Precipitation can effectively remove atmospheric particulate matter (Ouyang et al., 2015; Li et al., 2019). In comparison with other meteorological factors, the correlation between particulate matter concentration and total precipitation was the strongest except in summer $(r<-0.32$, Table 3$)$. In particular, the precipitation had the best cleaning effect on the particulate matter on the current day in winter (Fig. 4), which was consistent with the conclusions of Chen et al. (Chen et al., 2018). The cleaning effect of precipitation in spring and fall was relatively weak and mainly manifested as a cleaner next day or next two days. The particulate matter concentration in summer exhibited a weak correlation with the total precipitation (Table 3 ). This was primarily because the precipitation in summer mostly occured in the plum rain period and the period after the high temperature (Fig. S6). The particulate matter concentration and the total precipitation during the plum rain period exhibited significant negative correlations $\left(\mathrm{rPM}_{10}=-0.556^{* *}, \mathrm{rPM}_{2.5}=-0.506^{*}\right)$. The number of high-temperature and heat-wave days accounted for $38.0 \%$ of the entire summer season under low and sparse precipitation, while the particle concentration during this period was low (Fig. 1) and exhibited a weak negative correlation with precipitation $\left(\mathrm{rPM}_{10}=-0.043, \mathrm{rPM}_{2.5}=\right.$ -0.081 ). When the Spearman correlation coefficient between the particle concentration and the precipitation was based on the entire summer, a relatively high homogeneous rate likely appeared ( $\mathrm{Li}$ et al., 2009), resulting in a low correlation coefficient. In summary, when analyzing the characteristics of particulate matter pollution in the summer, special weather, such as high-temperature heat waves and plum rain, should be fully considered.

The correlation between precipitation and the relative humidity was strong $(r>0.7)$. The general trend showed that the moisture increased as the total precipitation increased. The current particulate matter concentrations in spring, fall, and winter exhibited significant negative correlations with the relative humidity on the previous day (Table 3 ), but significant positive correlations were found in summer. The natural sources dominated by crust and soil dust represent an important contribution to the composition of $\mathrm{PM}_{2.5}$ in Lin'an (Yang et al., 2006). Under precipitation or in a high humidity environment, humid soil can reduce the resuspended amount of soil dust (Hien et al., 2002; Li et al., 2019). In addition, the particulate matter suspended in the air will agglomerate under the action of water vapor until it settles on the ground surface (Chen et al., 2016a). These were two possible causes for lowering particle pollution as humidity increased in most seasons. However, in summer, the higher temperature were always accompanied by lower humidity $\left(\mathrm{r}=-0.74^{* *}\right.$, Fig. S3), while in other seasons, weak negative correlation or positive correlation between these two factors were more common. As analyzed above, low temperature would slower the decomposition of nitrates and ammonium salts, but the high moisture might be conducive to the hygroscopic growth of these aerosols in turn, and caused further increasing of particulate matter concentration positively (Wang et al., 2019).

Wind is the most important factor affecting atmospheric particulate matter. The wind direction determines the diffusion 


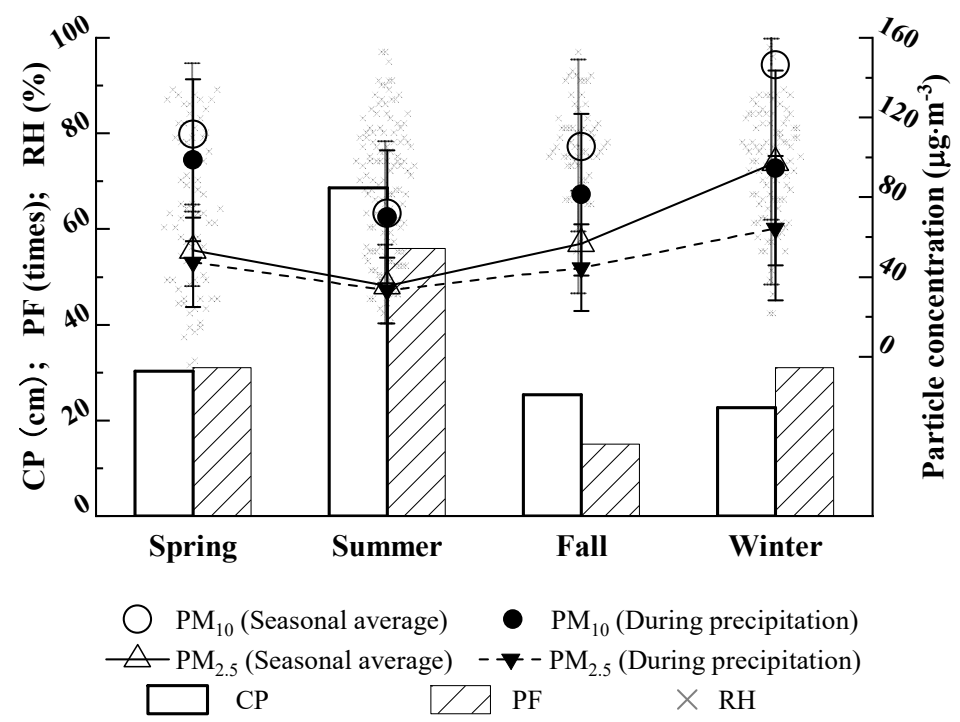

Fig. 4. The distribution of the quantity of cumulative precipitation, precipitation frequency and the concentrations of particulate matter in Lin'an during four seasons. "CP" represents cumulative precipitation, "PF" represents precipitation frequency.

direction of the particulate matter, and the wind velocity determines the dilution velocity and the degree of particulate matter (Ito et al., 2007; Singh et al., 2010; Chen et al., 2016b; Meng et al., 2019). The seasonal average wind speed during winter $\left(1.87 \pm 0.87 \mathrm{~m} \mathrm{~s}^{-1}\right)$ in Lin'an was slightly lower than that during the three other seasons $\left(2.08-2.42 \mathrm{~m} \mathrm{~s}^{-1}\right)$, and a strong wind readily occured in summer (the instantaneous wind velocity reaches or exceeds $10.8 \mathrm{~m} \mathrm{~s}^{-1}$ ); sometimes, a blustery wind (the instantaneous wind speed reaches or exceeds $13.9 \mathrm{~m} \mathrm{~s}^{-1}$, based on specifications for surface meteorological observation) would occur. The easterly wind (E and ENE) with speeds of $2.20 \mathrm{~m} \mathrm{~s}^{-1}$ prevailed throughout the year (Fig. S7). $\mathrm{PM}_{10}$ under this wind direction was higher than the annual average concentration, by approximately $14 \mu \mathrm{g} \mathrm{m}^{-3}$ (Fig. 5), and $\mathrm{PM}_{2.5}$ was higher by approximately $8 \mu \mathrm{g} \mathrm{m}^{-3}$. There was a significant difference in the distribution of particulate matter concentration under other wind directions (Mann-Whitney U test, $p \ll 0.01$ ). In summer, the particulate matter concentration under an easterly wind was 1.7 times higher than that observed for the other wind directions, and it was approximately 1.0-1.2 times higher than that for the three other seasons. The particulate matter concentrations under a noneasterly wind in the different seasons were lower than the seasonal average concentration by approximately $1.59 \%-25.31 \%$, and the wind speed was in the range of $0.40-6.00 \mathrm{~m} \mathrm{~s}^{-1}$. There is a distribution of industrial parks (e.g., Qingshan and Yuhang) on the eastern side of Lin'an, where the easterly wind would carry the particulate matter discharged in the parks to the urban area, therefore increasing the particle concentration in Lin'an. Furthermore, the terrain of Lin'an, i.e., three sides surrounded by mountains, is not favorable for the dilution and diffusion of pollutants under an easterly wind. In addition, the particulate matter discharged in the Yangtze River Delta economically developed area (e.g., Hangzhou and Shanghai) to the eastern side of Lin'an would also diffuse into this region under the action of an easterly wind, further increasing particulate matter pollution.
The Spearman correlation coefficient indicated that when the wind speed was high, the particulate matter concentration on the current day and the next day was relatively low. In particular, the correlation between the wind speed of the current day and the particulate matter concentration on the next day was the strongest. Except for spring, the correlations were significant. The data showed that the effect of wind on the particulate matter also had some hysteresis effects. The correlation between the wind speed and $\mathrm{PM}_{2.5}$ was much higher than that for $\mathrm{PM}_{10}$, which indicated that $\mathrm{PM}_{2.5}$ was more easily diluted with wind diffusion.

\section{Characteristics of the Particulate Matter Pollution in Summer}

Referring to the Division of Climate and Season implemented by the Chinese Meteorological Administration in 2012 (QX/T 152-2012), when the moving average temperature sequence is greater than or equal to $22^{\circ} \mathrm{C}$ for five consecutive days, the corresponding first date greater than or equal to $22^{\circ} \mathrm{C}$ is the start of summer (May 19), and September 24 was the last day of summer in Lin'an in 2013. The summer season spanned 129 days. The fluctuation of particulate matter concentration in summer exhibited a highlow-high variation (Fig. 1); the corresponding nodes were in early July and the middle of August. The summer season covered the plum rain period, high temperature and heat wave days. There were significant differences between the meteorological conditions of these two special time periods and the meteorological conditions of other periods. Therefore, based on the data of the daily highest temperature recorded at the automatic meteorological observation stations, we subdivided summer into the following four periods: the period before the plum rain (May 19-June 6, hereafter referred to as $\mathrm{S}_{\mathrm{P} 1}$ ), the plum rain period (June 7-June $30, \mathrm{~S}_{\mathrm{P} 2}$ ), the continuous high temperature period (July 1-August $18, \mathrm{~S}_{\mathrm{P} 3}$ ) and the period after the high temperature (August 19September 24, $\left.\mathrm{S}_{\mathrm{P} 4}\right)$. 


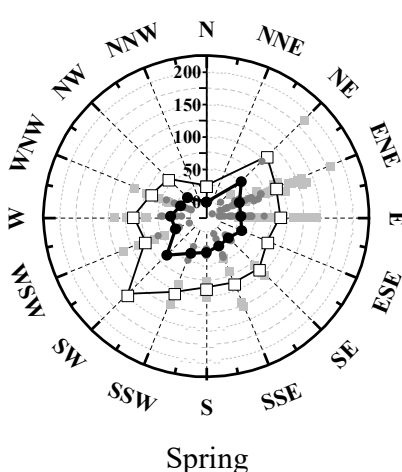

Spring

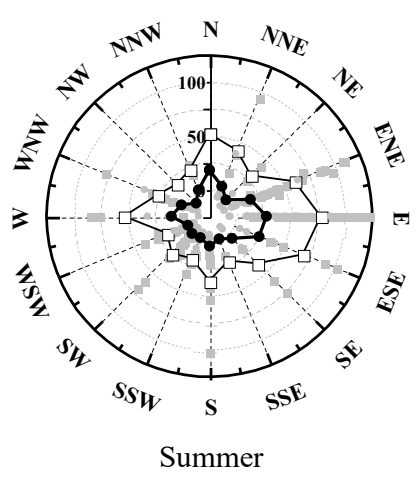

Summer

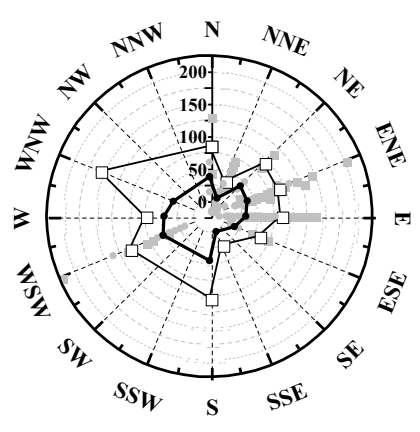

Fall

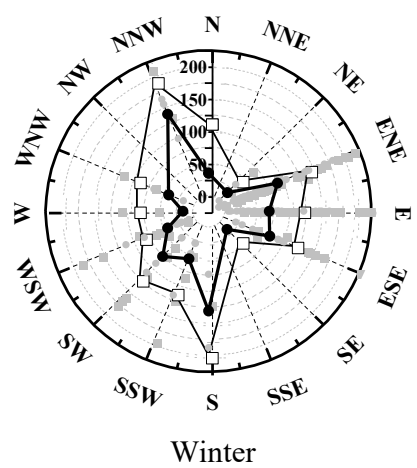

Winter

" Daily $\mathrm{PM}_{10} \quad \longrightarrow$ Average $\mathrm{PM}_{10} \quad$ - Daily $\mathrm{PM}_{2.5} \quad$ •-Average $\mathrm{PM}_{2.5}$

Fig. 5. Rose diagram for particle concentration $\left(\mu \mathrm{g} \mathrm{m}^{-3}\right)$ during four climatic seasons.

The cumulative precipitation during $\mathrm{S}_{\mathrm{P} 2}$ was $401.8 \mathrm{~mm}$ (Table 4, Fig. S6). During this time period, the precipitation on 13 days exceeded $2 \mathrm{~mm}$, and the relative humidity reached $78.29 \%$ (Fig S3). The daily average temperature was approximately $24.4^{\circ} \mathrm{C}$. The difference between the average temperature before the plum rain and after the high temperatures was within $\pm 1^{\circ} \mathrm{C}$. The easterly wind and the WNW wind (approximately $2.14 \mathrm{~m} \mathrm{~s}^{-1}$ ) prevailed, and the cumulative wind frequency was $66.7 \%$. The compliance rate of $\mathrm{PM}_{10}$ was $87.5 \%$. The $\mathrm{PM}_{2.5}$ met the standard on all but two days; the cumulative precipitation during $\mathrm{S}_{\mathrm{P} 1}$ was less than $10 \%$ of that during $\mathrm{S}_{\mathrm{P} 2}$, and the average wind velocity was lowest in the four stages with the narrowest variation amplitude. The easterly wind prevailed (68.4\%), and the average $\mathrm{PM}_{2.5}$ concentration was $54.32 \pm 20.39 \mu \mathrm{g} \mathrm{m}^{-3}$, which was higher than that in the plum rain season, by approximately $34.82 \%$; the daily precipitation under the high temperatures and heat wave days was generally less than $2 \mathrm{~mm}$. On July 31, it was $16.3 \mathrm{~mm}$, which was due to artificial precipitation. The relative humidity was in the range of $41 \%-75 \%$, and the daily average temperature reached $37.7^{\circ} \mathrm{C}$. The average pressure was close to that during $\mathrm{S}_{\mathrm{P} 2}$ $(992.90 \mathrm{hPa})$, and the average wind velocity exceeded $2.23 \mathrm{~m} \mathrm{~s}^{-1}$ during $\mathrm{S}_{\mathrm{P} 2}$, by approximately $0.28 \mathrm{~m} \mathrm{~s}^{-1}$. The southwesterly wind was the dominant wind direction (49.0\%), during which the air quality was generally good, and the particulate matter concentration was approximately $66 \%$ of the seasonal average concentration in summer; after the high temperature period, the precipitation quantity and frequency increased slightly, and the relative humidity was close to that in the plum rain season, while the pressure was only higher than that before the plum rain by approximately
$0.94 \mathrm{hPa}(996.64 \mathrm{hPa})$. The average wind velocity was comparable to that during $\mathrm{S}_{\mathrm{P} 3}$, but the dominant wind direction was primarily easterly $(64.8 \%)$, and the $\mathrm{PM}_{2.5} / \mathrm{PM}_{10}$ was the lowest among the four stages (0.47). The Kruskal-Wallis $\mathrm{H}$ test indicated that the distribution difference between the various meteorological factors, except for the wind speed, and particulate matter concentration at varying stages was significant. Subsequently, through the paired comparison in the Dunn-Bonferroni test, the $\mathrm{PM}_{2.5}$ concentration and $\mathrm{PM}_{10}$ concentration during $\mathrm{S}_{\mathrm{P} 3}$ exhibited significant differences from those of $\mathrm{S}_{\mathrm{P} 1}, \mathrm{~S}_{\mathrm{P} 2}$, and $\mathrm{S}_{\mathrm{P} 4}$. The concentration during $\mathrm{S}_{\mathrm{P} 2}$ was only significantly different from $\mathrm{S}_{\mathrm{P} 1}$, and no difference was found between $\mathrm{S}_{\mathrm{P} 2}$ and $\mathrm{S}_{\mathrm{P} 4}$.

The frequent and relatively high precipitation in $\mathrm{S}_{\mathrm{P} 2}$ was beneficial to remove the particulate matter from the air; therefore, the air was cleaner than in $\mathrm{S}_{\mathrm{P} 1}$. However, during $\mathrm{S}_{\mathrm{P} 3}$, the prevalent southeasterly wind and the relatively high wind speed were favorable for horizontal diffusion and dilution of the particulate matter. In addition, the relative humidity in the plum rain season was relatively high, which was conducive to the secondary formation of sulfates and nitrates or to the hygroscopic growth of the aerosols (Wang et al., 2019), increasing the volatile particulate matter concentration in the atmosphere. During $\mathrm{S}_{\mathrm{P} 3}$, the relative humidity was low, the diurnal temperature difference was large, the wind direction changed rapidly, and the atmosphere was active; therefore, the pollutants did not accumulate easily, and the continuous high temperature was not favorable for the generation of secondary particles (such as nitrate). Therefore, the fine particle pollution level in $\mathrm{S}_{\mathrm{P} 3}$ was significantly lower than that in other periods (approximately 0.60 times). In addition, lower human production activity during $\mathrm{S}_{\mathrm{P} 3}$ will

Table 4. Statistical summary of meteorological factors, $\mathrm{PM}_{10}$ and $\mathrm{PM}_{2.5}$ for various period in summer.

\begin{tabular}{llllllll}
\hline Period in summer & $\mathrm{AP} / \mathrm{hPa}$ & $\mathrm{T} /{ }^{\circ} \mathrm{C}$ & $\mathrm{RH} / \%$ & $\mathrm{P} / \mathrm{mm}$ & $\mathrm{WS} / \mathrm{m} \mathrm{s}^{-1}$ & $\mathrm{PM}_{10} / \mu \mathrm{g} \mathrm{m}^{-3}$ & $\mathrm{PM}_{2.5} / \mu \mathrm{g} \mathrm{m}^{-3}$ \\
\hline $\mathrm{S}_{\mathrm{P} 1}$ & $995.71 \pm 3.03$ & $23.73 \pm 2.59$ & $69.32 \pm 9.08$ & $2.09 \pm 4.09$ & $2.07 \pm 0.53$ & $107.58 \pm 29.87$ & $54.32 \pm 20.39$ \\
$\mathrm{~S}_{\mathrm{P} 2}$ & $992.89 \pm 3.53$ & $24.40 \pm 3.13$ & $78.29 \pm 6.88$ & $16.74 \pm 25.99$ & $2.23 \pm 0.90$ & $78.83 \pm 44.54$ & $40.29 \pm 25.81$ \\
$\mathrm{~S}_{\mathrm{P} 3}$ & $992.90 \pm 1.74$ & $31.14 \pm 1.93$ & $54.88 \pm 8.71$ & $0.50 \pm 2.36$ & $2.52 \pm 0.87$ & $47.51 \pm 14.55$ & $23.90 \pm 8.38$ \\
$\mathrm{~S}_{\mathrm{P} 4}$ & $996.64 \pm 4.36$ & $25.50 \pm 2.45$ & $79.19 \pm 9.69$ & $5.97 \pm 12.34$ & $2.58 \pm 1.14$ & $81.00 \pm 31.48$ & $38.30 \pm 16.82$ \\
Entire summer & $994.38 \pm 3.60$ & $27.18 \pm 3.98$ & $68.33 \pm 14.04$ & $5.32 \pm 14.27$ & $2.42 \pm 0.93$ & $71.79 \pm 35.91$ & $35.56 \pm 19.87$ \\
\hline
\end{tabular}

${ }^{*}$ For the division of the four periods in summer, refer to section of "Characteristics of the particulate matter pollution in summer". 
also reduce particulate matter pollution under these sustained conditions. Following the high-temperature and heat wave days, with the drop of air temperature and the increase of humidity in the air and the change in the dominant wind direction, the particulate matter pollution rebounded, but the relatively frequent precipitation events and higher wind speed resulted in particulate matter pollution comparable to that during $\mathrm{S}_{\mathrm{P} 2}$. Therefore, the variation in the particulate matter concentration during the summer exhibited a highlow-high pattern.

\section{CONCLUSIONS}

The characteristics of atmospheric particulate matter pollution and the effects of climatic seasonal differences, phase differences in summer and hysteresis of the meteorological factors on the particulate matter were analyzed in Lin'an based on particle concentration and meteorological data from January 2013 through December 2013. The results showed that:

a) The annual average $\mathrm{PM}_{10}$ and $\mathrm{PM}_{2.5}$ concentrations in Lin'an during 2013 were $105.88 \pm 59.46 \mu \mathrm{g} \mathrm{m}^{-3}$ and $59.54 \pm$ $44.34 \mu \mathrm{g} \mathrm{m}^{-3}$, respectively, greatly exceeding the yearly CAAQS Grade II standards. In particular, the daily CAAQS Grade II standard compliance rate for $\mathrm{PM}_{2.5}$ was less than that for $\mathrm{PM}_{10}$. Throughout the entire year, for $82.19 \%$ of the days, the atmospheric particulate matter was the primary air pollutant.

b) Both $\mathrm{PM}_{10}$ and $\mathrm{PM}_{2.5}$ exhibited seasonal trends, and the distribution difference of the particulate matter concentration in different climatic seasons was significant $(p \ll 0.01)$. The $\mathrm{PM}_{2.5}$ concentration in winter was significantly higher than that in summer (2.7 times), and its compliance rate $(46.5 \%)$ was much lower than that in summer $(95.3 \%)$. The difference between spring and fall was not significant. The average concentrations of $\mathrm{PM}_{10}$ and $\mathrm{PM}_{2.5}$ on the workdays were lower than on legal holidays, by $5.82 \mu \mathrm{g} \mathrm{m} \mathrm{m}^{-3}$ and $4.86 \mu \mathrm{g} \mathrm{m}^{-3}$, respectively, and no significant difference was found at the seasonal or yearly scale.

c) The hysteresis effect of meteorological factors on the concentration of particulate matter was observed in this study, and seasonal differences of this effect were analyzed. Both $\mathrm{PM}_{10}$ and $\mathrm{PM}_{2.5}$ exhibited a significant positive correlation with the pressure 1-2 days earlier in spring, summer, and fall and exhibited an extremely significant negative correlation with the temperature 2-3 days earlier in summer and fall. The lower the relative humidity in spring, fall, and winter, the more serious the pollution on the next day, but the opposite occurred in summer. The precipitation significantly reduced the particulate matter concentration on the current day and on the next day (except in summer), but the effect of wind speed was relatively weak. The particulate matter concentration under the dominance of an easterly wind (of approximately $2.2 \mathrm{~m} \mathrm{~s}^{-1}$ ) was approximately 1.3 times higher than that under other wind directions, and the difference was extremely significant.

d) The average $\mathrm{PM}_{2.5}$ concentration during the period before the plum rain in summer was $54.32 \pm 20.39 \mu \mathrm{g} \mathrm{m}^{-3}$. The frequent precipitation during the plum rain period improved the air quality significantly compared to the period before the plum rain, and the fine particle pollution level under the high-temperature and heat wave days was significantly lower than that in other periods (approximately 0.60 times). After the high-temperature and heat wave days, the particle concentration was higher than that during the plum rain period, but no significant difference was observed. The variation in the particulate matter concentration during the entire summer exhibited a high-low-high variation.

\section{ACKNOWLEDGMENTS}

This research received funding from the National Science Foundation of China (41471442 and 41101421).

\section{SUPPLEMENTARY MATERIALS}

Supplementary data associated with this article can be found in the online version at http://www.aaqr.org.

\section{REFERENCES}

Bai, J.H., Guenther, A., Turnipseed, A., Duhl, T. and Greenberg, J. (2017). Seasonal and interannual variations in whole-ecosystem BVOC emissions from a subtropical plantation in China. Atmos. Environ. 161: 176-190.

Chen, B., Lu, S.W. and Li, S.N. (2016a). Dynamic analysis of $\mathrm{PM}_{2.5}$ concentrations in urban forests in Beijing for variousweather conditions. Acta. Ecol. Sin. 36: 1391-1399.

Chen, J., Jiang, H., Wang, B., Xiao, Z.Y., Jiang Z.S., Zhou, G.M. and Yu, S.Q. (2012). Aerosol optical properties from sun photometric measurements in Hangzhou district, China. Int. J. Remote. Sens. 33: 2451-2461.

Chen, T., He, J., Lu, X.W., She, J.F. and Guan, Z.Q. (2016b). Spatial and Temporal Variations of $\mathrm{PM}_{2.5}$ and Its Relation to Meteorological Factors in the Urban Area of Nanjing, China. Int. J. Environ. Res. Public Health 13: 921.

Chen, Z.Y., Xie, X.M., Cai, J., Chen, D.L., Gao, B.B., He, B., Cheng, N.L. and Bing, X. (2018). Understanding meteorological influences on $\mathrm{PM}_{2.5}$ concentrations across China: A temporal and spatial perspective. Atmos. Chem. Phys. 18: 5343-5358.

Finlayson-Pitts, B.J. (2009). Reactions at surfaces in the atmosphere: Integration of experiments and theory as necessary (but not necessarily sufficient) for predicting the physical chemistry of aerosols. Phys. Chem. Chem. Phys. 11: 7760-7779.

Guo, H., Wang, Y.G. and Zhang, H.L. (2017). Characterization of criteria air pollutants in Beijing during 2014-2015. Environ. Res. 154: 334-344.

Hassan, S.K., El-Abssawy, A.A. and Khoder, M.I. (2013). Characteristics of gas-phase nitric acid and ammoniumnitrate- sulfate aerosol, and their gas-phase precursors in a suburban area in Cairo, Egypt. Atmos. Pollut. Res. 4: 117-129.

Heal, M.R., Naysmith, P., Cook, G.T., Xu, S., Duran, T.R. and Harrison, R.M. (2011). Application of ${ }^{14} \mathrm{C}$ analyses to source apportionment of carbonaceous $\mathrm{PM}_{2.5}$ in the UK. 
Atmos. Environ. 45: 2341-2348.

Hien, P.D., Bac, V.T., Tham, H.C., Nhan, D.D. and Vinh, L.D. (2002). Influence of meteorological conditions on $\mathrm{PM}_{2.5}$ and $\mathrm{PM}_{2.5-10}$ concentrations during the monsoon season in Hanoi, Vietnam. Atmos. Environ. 36: 3473 3484.

Hu, J.L., Wang, Y.G., Ying, Q. and Zhang, H.L. (2014a). Spatial and temporal variability of $\mathrm{PM}_{2.5}$ and $\mathrm{PM}_{10}$ over the North China Plain and the Yangtze River Delta, China. Atmos. Environ. 95: 598-609.

Hu, X.M., Ma, Z.Q., Lin, W.L., Zhang, H.,L. Hu, J.L., Wang, Y., Xu, X.B., Fuentes, J.D. and Xue, M. (2014b). Impact of the Loess Plateau on the atmospheric boundary layer structure and air quality in the North China Plain: a case study. Sci. Total Environ. 499: 228-237.

Huang, F.F., Li, X., Wang, C., Xu, Q., Wang, W., Luo, Y.X., Tao, L.X., Gao, Q., Guo, J., Chen, S.P., Cao, K., Liu, L., Gao, N., Liu, X.T., Yang, K., Yan, A.S. and Guo, X.H. (2015). $\mathrm{PM}_{2.5}$ spatiotemporal variations and the relationship with meteorological factors during 2013-2014 in Beijing, China. PLoS One 10: e0141642.

Huang, K., Zhuang, G., Lin, Y., Fu, J.S., Wang, Q., Liu, T., Zhang, R., Jiang, Y., Deng, C., Fu, Q., Hsu, N.C. and Cao, B. (2012). Typical types and formation mechanisms of haze in an Eastern Asia megacity, Shanghai. Atmos. Chem. Phys. 12: 105-124.

Ito, K., Thurston, G.D. and Silverman, R.A. (2007). Characterization of $\mathrm{PM}_{2.5}$, gaseous pollutants, and meteorological interactions in the context of time-series health effects models. J. Exposure Sci. Environ. Epidemiol. 17: S45-S60.

Jaagus, J. and Ahas, R. (2000). Space-time variations of climate seasons and their correlation with the phenological development of nature in Estonia. Clim. Res. 15: 207-219.

Li, J., Sun, C.B., Liu, X.D., Dong, S.P., Guo, J., Wang, Y., An, X.X. and Liu, F. (2009). Non-parameter statistical analysis of impacts of meteorological conditions on PM concentration in Beijing. Acta. Sci. Circum. 22: 663-669.

Li, X.Y., Song, H.Q., Zhai, S.Y., Lu, S.Q., Kong, Y.F., Xia, H.M. and Zhao, H.P. (2019). Particulate matter pollution in Chinese cities: Areal-temporal variations and their relationships with meteorological conditions (2015-2017). Environ. Pollut. 246: 11-18.

Li, Y., Schwandner, F.M., Sewell, H.J., Zivkovich, A., Tigges, M., Raja, S., Holcomb, S., Molenar, J.V., Sherman, L., Archuleta, C., Lee, T. and Collett Jr, J.L. (2014). Observations of ammonia, nitric acid, and fine particles in a rural gas production region. Atmos. Environ. 83: 80-89.

Li, Y.Y., Yan, J.P. and Sui, X.B. (2012). Tropospheric temperature inversion over central China. Atmos. Res. 116: $105-115$.

Liang, L.L., Sun, J.Y., Zhang, Y.M., Liu, C., Xu, W.Y., Zhang, G., Liu, X.Y. and Ma, Q.L. (2018). Comparison of chemical components characteristics of $\mathrm{PM}_{2.5}$ between haze and clean periods during summertime in Lin'an. Environ. Sci. 39: 3042-3050.

Meng, C., Cheng, T.H., Gu, X.F., Shi, S.Y., Wang, W.N., Wu, Y. and Bao, F.W. (2019). Contribution of meteorological factors to particulate pollution during winters in Beijing. Sci. Total Environ. 656: 977-985.

Ouyang, W., Guo, B.B., Cai, G.Q., Li, Q., Han, S., Liu, B. and Liu, X.G. (2015). The washing effect of precipitation on particulate matter and the pollution dynamics of rainwater in downtown Beijing. Sci. Total Environ. 505: 306-314.

Shi, S.S., Wang, H.L., Zhu, B., Lin, X., Guo, T., Sha, D.D, Jiang, L., Zhang, Y.X. and Shi, Y.Z. (2017). Source apportionment and size distribution of aerosols at Lin'an atmosphere regional background station during winter. Environ. Sci. 38: 4024-4033.

Singh, R., Sharma, B.S. and Chalka, S.N. (2010). Seasonal air quality profile of inorganic ionic composition of $\mathrm{PM}_{10}$ near Taj Mahal in Agra, India. Environ. Monit. Assess. 168: 195-203.

Sun, Y.L., Zhuang, G.S., Wang, Y., Han, L.H., Guo, J.H., Dan, M., Zhang, W.J., Wang, Z.F. and Hao, Z.P. (2004). The air-borne particulate pollution in Beijing - concentration, composition, distribution and sources. Atmos. Environ. 38: 5991-6004.

Tian, G.J., Qiao, Z. and Xu, X.L. (2014). Characteristics of particulate matter $\left(\mathrm{PM}_{10}\right)$ and its relationship with meteorological factors during 2001-2012 in Beijing. Environ. Pollut. 192: 266-274.

Wang, H., Li, J.H., Peng, Y., Zhang, M., Che, H.Z. and Zhang, X.Y. (2019). The impacts of the meteorology features on $\mathrm{PM}_{2.5}$ levels during a severe haze episode in central-east China. Atmos. Environ. 197: 177-189.

Wang, M.T., Zhu, B., Wang, H.L., Xue, G.Q., He, J., Xu, H.H. and Cao, J.F. (2015). Composition and regional characteristics of atmosphere aerosol and its water soluble ions over the Yangtze River Delta region in a winter haze period. Environ. Sci. 36: 2337-2345.

Xu, J.M., Yan, F.X., Xie, Y., Wang, F.Y., Wu, J.B. and Fu, Q.Y. (2015). Impact of meteorological conditions on a nine-day particulate matter pollution event observed in December 2013, Shanghai, China. Particuology 20: 6979.

Yadav, S., Praveen, O.D. and Satsangi, P.G. (2015). The effect of climate and meteorological changes on particulate matter in Pune, India. Environ. Monit. Assess. 187: 402.

Yang, D.Z., Yan, P., Zhang, Y.M., Xu, J. and Wang, S.F. (2006). Aerosol properties at lin'an WMO background station. Quaternary Sci. 26: 733-741.

Yue, Y., Li, J.J. and Ma, Q.L. (2017). Variation characteristics of $\mathrm{PM}_{10}$ and its influencing factors at Lin'an regional background station in Yangtze River Delta region during 2010 2015. China Environ. Sci. 37: 2877-2887.

Zhang, H., Wang, Y., Hu, J., Ying, Q. and Hu, X.M. (2015). Relationships between meteorological parameters and criteria air pollutants in three megacities in China. Environ. Res. 140: 242-254.

Received for review, March 6, 2019 Revised, September 24, 2019 Accepted, September 24, 2019 